\title{
PENINGKATAN KOMPETENSI DAN KINERJA TUKANG PADA PEKERJAAN PASANGAN BATA DENGAN ALAT BANTU
}

\section{IMPROVEMENT OF BUILDERS COMPETENCE AND PERFORMANCE IN CONDUCTING BRICK'S WORK WITH TOOLS}

\author{
Try Sugiyarto ${ }^{1)}$, Ainusalbi Al Ikhsan ${ }^{2)}$, Sulha $^{3)}$, Baso Mursidi ${ }^{4)}$, Statiswaty $^{5)}$ \\ ${ }^{1,2,3,4}$ Program Pendidikan Vokasi, Universitas Halu Oleo \\ ${ }^{5}$ Fakultas Teknik, Universitas Halu Oleo \\ ${ }^{1}$ Email: trysaja@uho.ac.id
}

\begin{abstract}
Abstrak: Pemasangan batu bata secara umum dilakukan dengan konvensional. Hal ini karena kemahiran tukang (batu) pada umumnya diperoleh secara belajar sendiri (autodidact) tanpa adanya kursus tukang (pelatihan) atau yang dari semula berperan sebagai pekerja (bantu) lalu memberanikan diri menjadi Tukang (batu) dengan modal melihat dan mencoba. Permasalahan yang sering muncul adalah kualitas pemasangan tidak rapi, efektivitas waktu yang tidak maksimal serta efisiensi campuran yang banyak terbuang. Oleh karena itu dibutuhkan suatu pengarahan dan pelatihan serta pendampingan penggunaan alat bantu guna mendukung kualitas pasangan menjadi rapi, efektivitas pemasangan yang makin meningkat volumenya, serta optimalisasi campuran agar tidak terbuang. Sehingga kompetensi menjadi meningkat, dan volume pekerjaan juga meningkat.
\end{abstract}

Kata Kunci: Pekerja konstruksi, Kompetensi, Pasangan batu bata.

\begin{abstract}
Installation of bricks is generally done with conventional because the workers' skill is usually obtained by autodidact without a training course and then ventured into Expert Worker (stones) by seeing and trying. Problems that often arise are the quality of untidy installation, time not maximal effectiveness, and the mixture's efficiency wasted. Therefore, it takes a briefing and training, and assistance to use tools to support work quality to be neat, the effectiveness of installation increases in volume, and optimization of mixtures not to be wasted. So that competence becomes increased, and the volume of work increases.
\end{abstract}

Keywords: construction workers, competence, masonry.

\section{PENDAHULUAN}

Dalam merencanakan atau membuat suatu bangunan, baik itu bangunan tingkat tinggi atau bangunan sederhana, tidak lepas dari adanya elemen ruang yang biasa disebut dinding (Suhendra \& , Elvira Handayani, 2015). Material dinding merupakan suatu bagian yang cukup penting dalam suatu proyek konstruksi (Purwanti, 2014).

Batu bata adalah salah satu bahan bangunan (Indra, Edison, Nofrianto, \& Kurnia $P$, 2016) yang sangat banyak dipergunakan untuk pembuatan konstruksi 
Bangunan (Surya Narayana Raju, Srikanth Reddy, Raju, \& Jagadeep, 2019) dan salah satu diantaranya adalah pembuatan konstruksi dinding bata (Ornam, Kimsan, Ngkoimani, \& Santi, 2017). Untuk pembuatan pasangan batu bata ini diperlukan pengetahuan dan keterampilan agar pasangan konstruksi tersebut rapi, kuat dan mudah mengerjakannya (Widjaja Thomas Brunner, 2012), apalagi pada umumnya pasangan batu bata ini akan di tindak lanjut dengan pekerjaan plesteran disamping pasangan indah yang tanpa plesteran (Harun, 2013).

Dalam proses pekerjaan pasangan batu bata di lapangan, kelompok masyarakat tukang bangunan umumnya memiliki permasalahan yang sama yakni jarak perekat (spesi/mortar) batu bata terlalu tebal atau bahkan terlalu tipis seperti pada Gambar 1a (Ekart \& Heinz, 2005). Selain itu, dimensi batu bata tidak sama tinggi (Prayuda, Setyawan, \& Saleh, 2018), sehingga apabila di pasang bata tidak berada pada garis lurus ditunjukkan pada Gambar 1b. Metode konstruksi yang kurang baik dapat menimbulkan kerugian material, waktu dan tenaga. Selain itu, bangunan yang dihasilkan pun terasa tidak nyaman, estetika kurang dan lebih parahnya lagi tidak aman atau rawan retak/rusak (Kurniaty, 2010). Akibatnya diperlukan perbaikan dengan biaya yang tidak sedikit, bangunan tersebut tidak dapat digunakan sesuai waktu yang ditentukan sehingga menjadi masalah yang serius (Abdul \& Vendie, 2016).

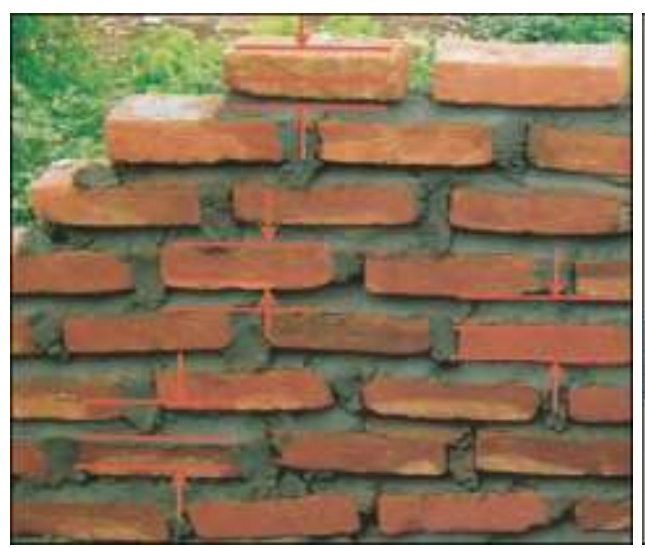

(a)

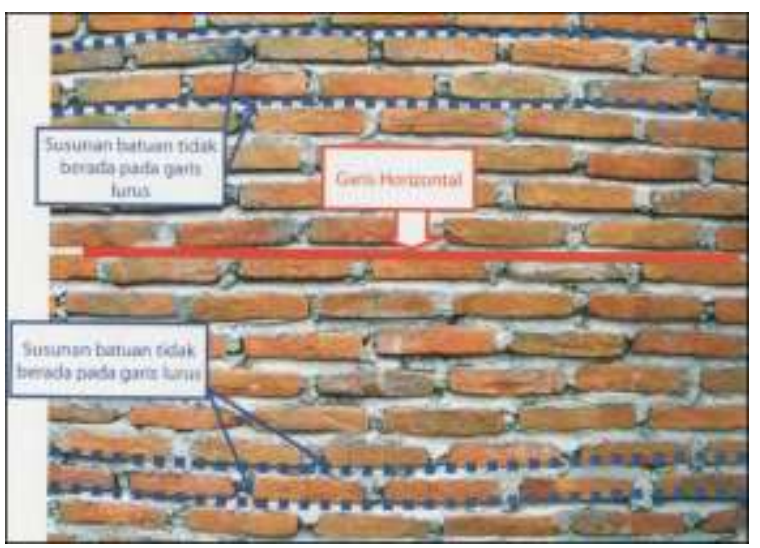

(b)

Gambar 1. Spesi perekat batu bata pada pasangan $1 / 2$ bata

Produktivitas tenaga kerja yang baik sangat diperlukan untuk keberhasilan proyek kontruksi (Fulford \& Standing, 2014). Produktivitas tenaga kerja akan sangat berpengaruh juga terhadap besarnya keuntungan atau kerugian suatu proyek (Dakhli \& Lafhaj, 2017). Dalam pelaksanaan dilapangan hal tersebut 
terkadang bisa terjadi dikarenakan tenaga kerja yang kurang efektif didalam pekerjaannya (Hartono, 2016).

Kota Kendari merupakan Ibukota Provinsi Sulawesi Tenggara yang terdiri dari 11 kecamatan. Kecamatan yang menjadi fokus kegiatan yaitu kecamatan Anduonohu dan Kecamatan Kambu yang sedang giat tumbuh dengan perumahanperumahan. Beberapa dijumpai tukang yang sedang 'memborong' dan mengerjakan pekerjaan pasangan dinding. Bekerjasama dengan tukang-tukang tersebut yang secara berkelompok dijadikan mitra pada kegiatan pengabdian ini.

Permasalahan mitra adalah kelompok kerja yang terdiri dari tukang dan pekerja pada saat melakukan pekerjaan pasangan dinding bata lebih mengutamakan volume pekerjaan sehingga kompetensi dan kinerja bukan menjadi prioritas utama. Hal ini terjadi karena sistem kerja yang diterapkan adalah borongan, sehingga semakin cepat pekerjaan selesai maka semakin cepat pula bayaran diterima. Selain itu pula pengawasan terhadap proses yang dilakukan relatif minim karena yang di jadikan fokus utama adalah hasil akhir pekerjaan.

Selain itu, status kompetensi tukang (Widiasanti, Fridestu, Rochyadi, \& Anisah, 2018) yang tidak memiliki Sertifikasi Kompetensi Terampil, sehingga kemampuan yang dimiliki merupakan kemampuan 'kebiasaan' atau merupakan turun temurun. Hal ini menyebabkan pekerjaan yang dilaksanakan atau diselesaikan tidak berdasarkan metode-metode kerja yang tepat namun berdasarkan kebiasaan dikalangan mereka.

Disisi non teknis, kemauan dan kemampuan para Tukang serta pekerja untuk melakukan updating keilmuan maupun keterampilan terasa minim. Bahkan untuk sekedar menggunakan smartphone yang dimiliki guna mengakses beritaberita tentang peningkatan Kompetensi Pekerja Konstruksi dari PUPR atau dengan menyaksikan video-video dengan konten metode kerja konstruksi tidak pernah dilakukan.

Secara terinci permasalahan yang dihadapi mitra adalah sebagai berikut:

1. Pengetahuan akan teknologi bahan masih minim.

2. Pengetahuan akan kompetensi dasar pekerja konstruksi masih minim

3. Pengetahuan tentang optimalisasi kualitas masih minim

4. Pengetahuan tentang optimalisasi kinerja masih minim 
INTEGRITAS : Jurnal Pengabdian

Vol 5 No 1 Juli 2021

ISSN $2580-7978$ (cetak) ISSN 2615-0794 (online)

5. Pengetahuan akan peran alat kerja pendukung yang masih minim.

Dengan adanya kegiatan pengabdian kepada masyarakat ini diharapkan menjadi penghubung antara perguruan tinggi dengan masyarakat sehingga terjalain keharmonisan dalam aplikasi keilmuan (Akmal Abdullah, Mauli Kasmi, Karma, \& Ilyas, 2020).

\section{METODE}

Pada Gambar 2 berikut merupakan tahapan pelaksanaan kegiatan dimulai dari desain alat bantu, pembuatan alat, pendampingan penggunaan alat, dan kerja mandiri mitra.

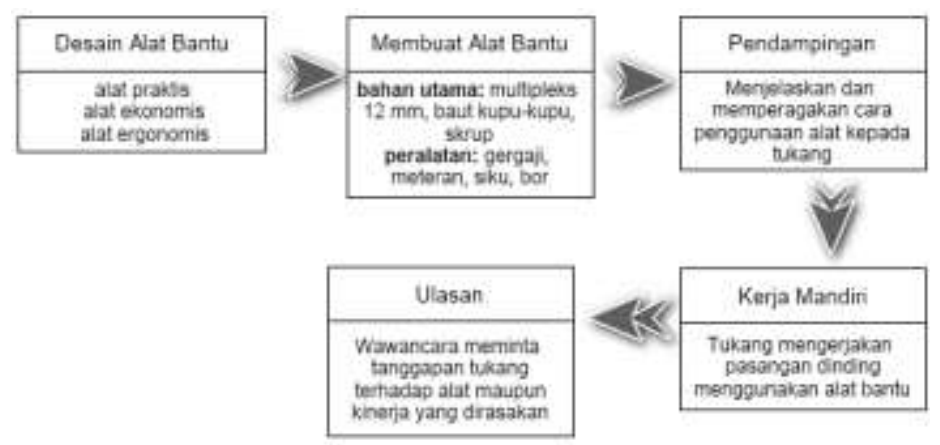

Gambar 2. Alur Tahapan Pelaksanaan kegiatan

Kegiatan pengabdian ini melibatkan 11 kelompok kerja terdiri dari Tukang dan Pekerja yang tersebar di Kecamatan Anduonohu dan Kambu dengan dua jenis pekerjaan pasangan bata yaitu dinding rumah dan dinding pagar. Metode pelaksanaan kegiatan adalah metode ceramah (pengarahan), pendampingan penggunaan alat dan diskusi dilokasi kerja.

\section{HASIL DAN PEMBAHASAN}

Pendampingan penggunaan alat bantu dalam pekerjaan pasang dinding batu bata bagi kelompok pekerja di Kecamatan Anduonohu dan Kecamatan Kambu Kota Kendari berlangsung selama 2 minggu. Tersebar di 11 titik lokasi dan terbagi menjadi 2 jenis pekerjaan pasangan dinding batu bata yaitu dinding rumah dan dinding pagar. 
Adapun kegiatan yang dilakukan adalah:

1. Desain Alat
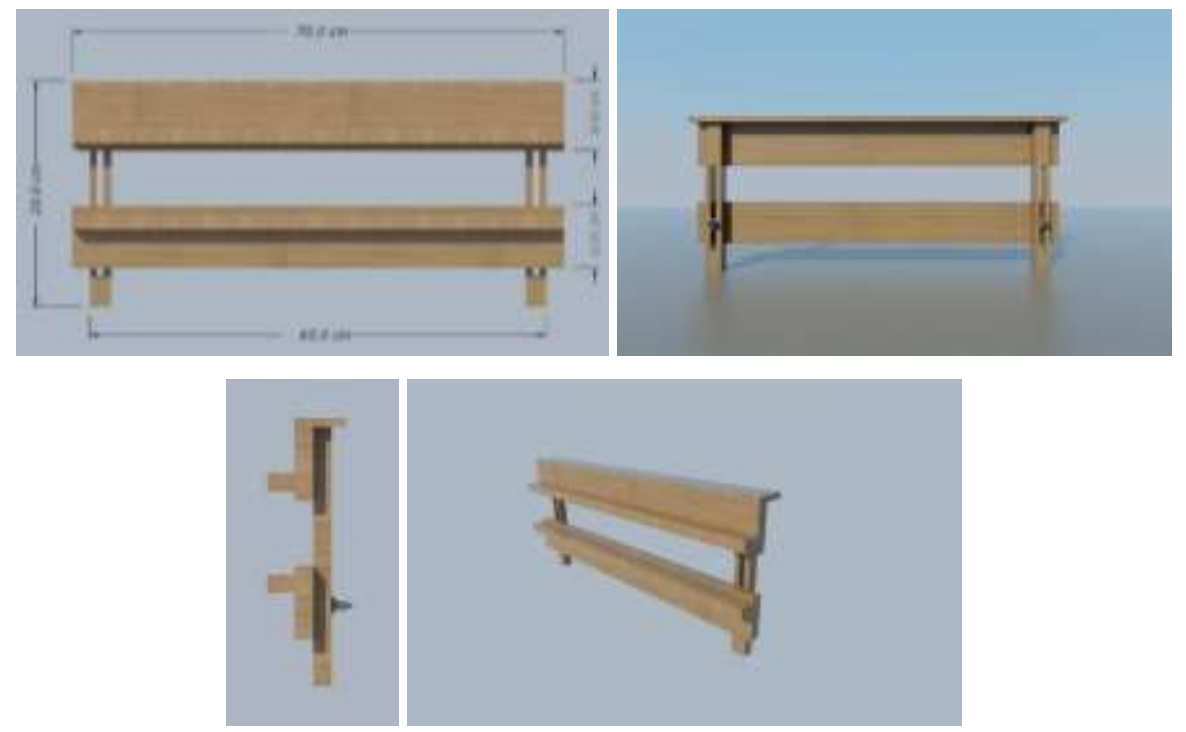

Gambar 3. Tampilan Desain alat di Aplikasi Sketchup

Desain alat bantu menggunakan aplikasi Sketchup, dengan mempertimbangkan praktis dan ergonomis. Gambar 3 menujukkan dimensi, tampak depan, tampak samping dan perspektif alat bantu yang akan dibuat. Dimensi keseluruhan alat yaitu $70 \mathrm{~cm}$ x $28 \mathrm{~cm}$, dengan penggunaan baut kupukupu sehingga lebar permukaan sentuh dengan bata dapat disesuaikan.

2. Pembuatan Alat
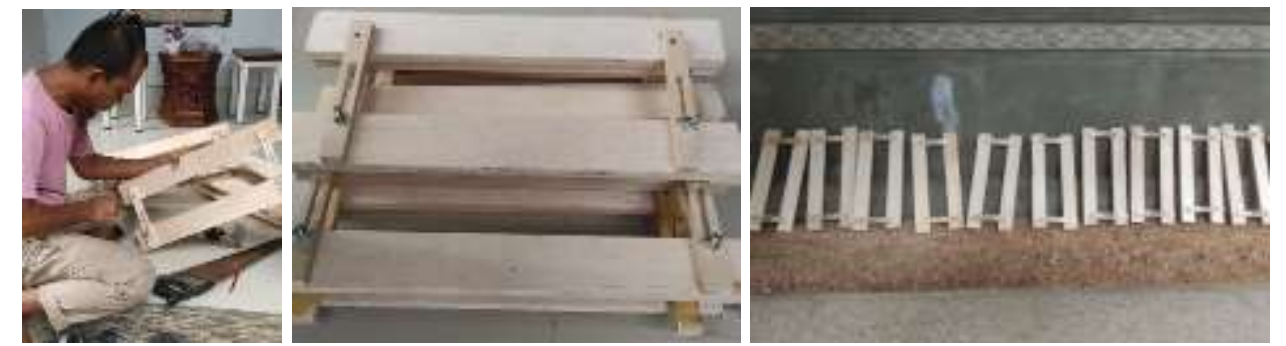

Gambar 4. Proses Pembuatan Alat

Pembuatan alat dilakukan dengan menggunakan peralatan tukang kayu standar, yakni: gergaji, meteran, siku dan bor. Bahan utama alat ini dipilih yang ekonomi dan tentunya mudah dibuat maupun dirakit, yakni: multipleks $12 \mathrm{~mm}$, baut kupu-kupu dan skrup. Gambar 4 menunjukkan perakitan alat bantu dengan peralatan tukang kayu pada umumnya serta tampilan alat yang telah dirakit dan siap pakai. 


\section{Pendampingan}

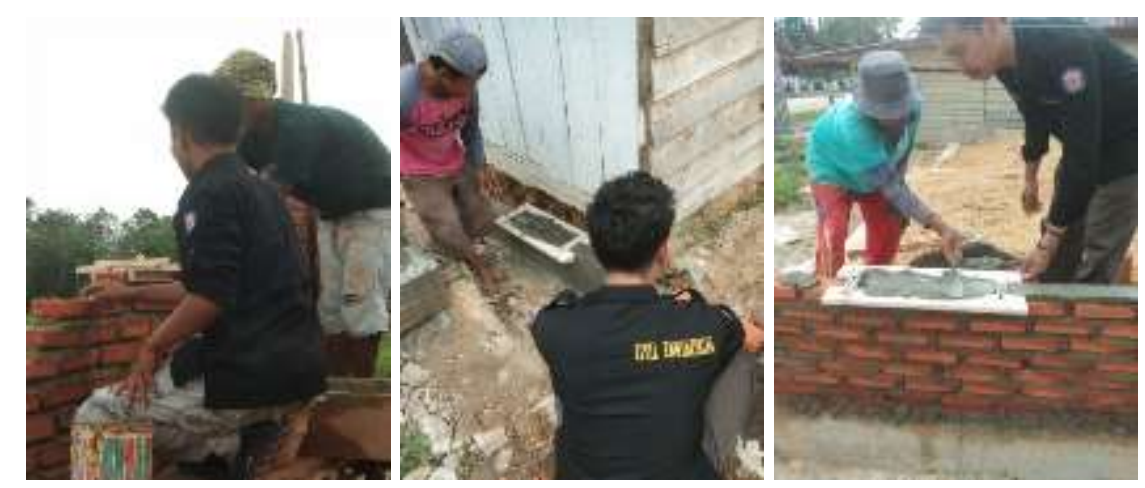

Gambar 5. Pendampingan dan Pengarahan

Memperkenalkan alat bantu langsung kepada tukang yang sedang bekerja lebih efektif karena tukang dapat mencoba dilokasi kerja. Gambar 5 memperlihatkan keterlibatan tim fokus pada fungsi dan kegunaan alat dalam pekerjaan pasangan dinding batu bata dengan uji coba langsung dilokasi kerja. Komunikasi dilakukan dengan santai dan lebih mengutamakan pendekatan persuasif sehingga penerimaan tim disela-sela pekerjaan para tukang tidak mengganggu atau bahkan teracuhkan.

\section{Kerja Mandiri}

Setelah diberikan alat bantu, dan cukup waktu untuk menyesuaikan selanjutnya tukang melakukan eksplorasi mandiri terhadap pekerjaan pasangan dinding dilokasi kerja. Gambar 6 memperlihatkan beberapa tukang yang menggunakan alat bantu guna mendukung efektifitas dan efisiensi pekerjaan. Pekerjaan yang dilakukan oleh tukang batu dibatasi pekerjaan pasangan batu bata untuk dinding rumah (perumahan) dan dinding pagar (perumahan dan batas tanah).
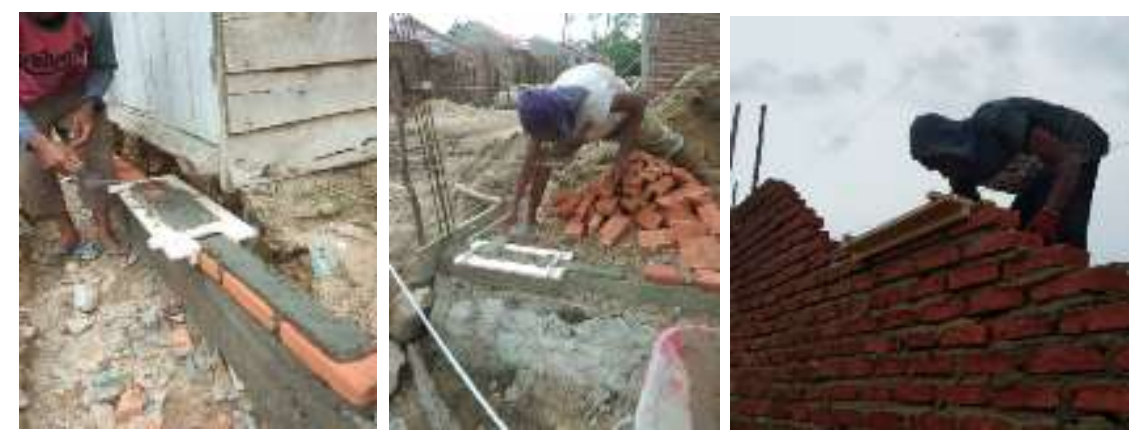

Gambar 6. Penggunan alat bantu oleh tukang dengan mandiri 
Secara keseluruhan, pelaksanaan kegiatan terlaksana dengan lancar tanpa kendala berarti. Tim bertugas dengan penuh dedikasi ditunjang dengan penerimaan Mitra yang hangat dan merespon postif kegiatan ini.

Pada kegiatan ini beberapa fakta ditemui dilapangan antara lain:

1. Pendidikan

$100 \%$ tukang yang merupakan mitra tidak menyelesaikan pendidikan dasar hingga tuntas. Hal ini dilatar belakangi oleh faktor ekonomi keluarga dan diperparah dengan budaya 'enggan' sekolah dilingkungan keluarga.

2. Kompetensi

$100 \%$ tukang yang merupakan mitra tidak memiliki sertifikat tenaga terampil atau SKT. Bahkan 8 dari 11 orang tidak mengetahui apa dan untuk apa SKT tersebut.

3. Pelatihan

$100 \%$ tukang yang merupakan mitra tidak pernah mendapatkan pelatihan kerja, baik dari pemberi kerja maupun dari instansi terkait.

4. Pengalaman

$100 \%$ tukang yang merupakan mitra bekerja menjadi tukang batu turun temurun dan hanya mengandalkan pengalaman. Durasi pengalaman yang cukup lama dengan rentan 5 tahun - 12 tahun telah menjadi tukang.

5. Komitmen

$100 \%$ tukang yang merupakan mitra berharap mendapat pelatihan kerja guna meningkatkan kompetensi.

Dari fakta-fakta yang diperoleh dilapangan saat wawancara dan diskusi sambil bekerja, maka tim kegiatan pengabdian juga memberi pengarahan seputar dunia konstruksi antara lain:

1. Memberi petunjuk cara akses pranala melalui smartphone yang miliki pada informasi-informasi dunia konstruksi. Youtube hingga ke website Direktorat Jenderal Bina Konstruksi Kementerian Pekerjaan Umum dan Perumahan Rakyat.

2. Diskusi konstruksi terkait metode-metode praktis hingga ke pengetahuan bahan. 
3. Memberi informasi seputar Sertifikat Keterampilan (SKT), jenis bidang dan sub bidang serta prosedur memperolehnya.

Pengukuran kinerja melalui indikator volume pekerjaan pasangan dinding bata terhadap 5 kelompok tukang menunjukkan peningkatan volume yang cukup signifikan. Ilustrasi perbedaan peningkatan volume penggunaan alat bantu disajikan pada Gambar 7 berikut.

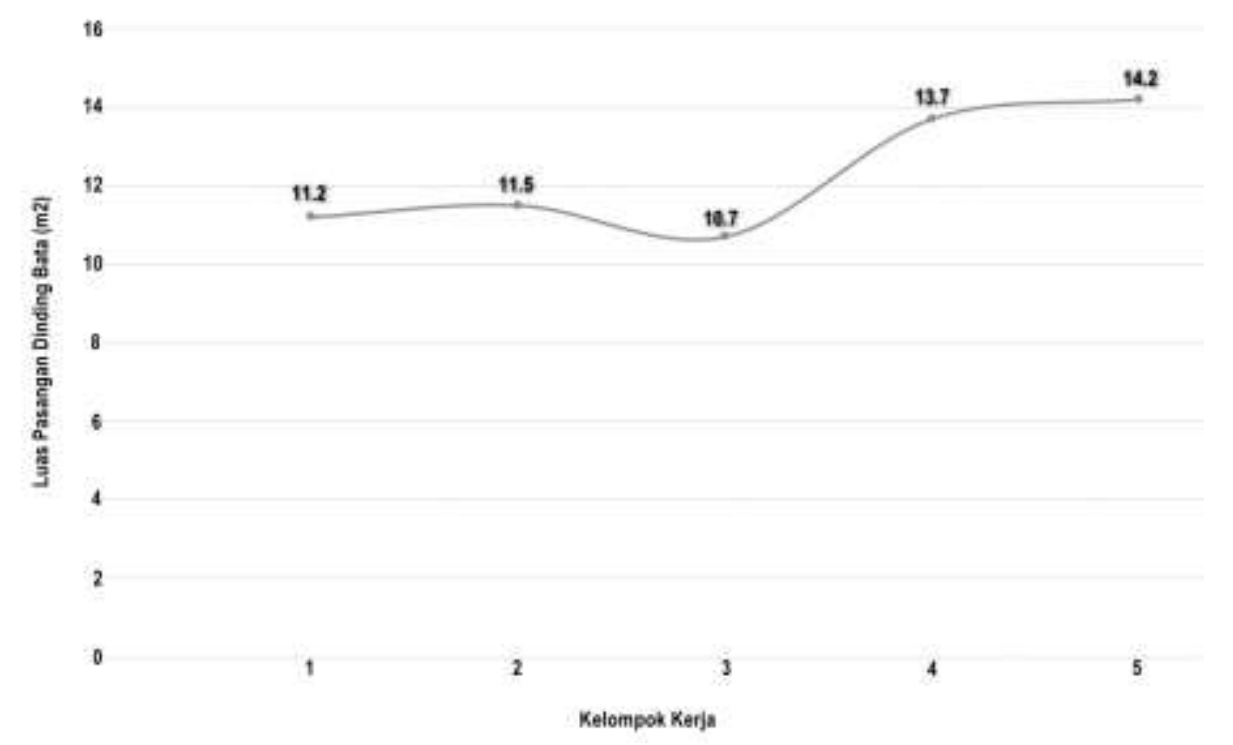

Gambar 7. Grafik perbandingan luas pasangan dinding bata antar kelompok kerja

Terlihat pada gambar perbandingan volume hasil pekerjaan antar kelompok kerja yang diamati yaitu Kelompok 1, 2 dan 3 merupakan kelompok yang tidak menggunakan alat bantu memperoleh hasil luas pasangan dinding bata sebesar $11.2 \mathrm{~m}^{2}, 11.5 \mathrm{~m}^{2}$, dan $10.7 \mathrm{~m}^{2}$. Sedangkan kelompok kerja yang menggunakan alat bantu adalah kelompok 4 dan 5 memperoleh hasil luas pasangan dinding bata sebesar $13.7 \mathrm{~m}^{2}$ dan $14.2 \mathrm{~m}^{2}$.

Perbandingan hasil tersebut menunjukkan terdapat perubahan hasil antara kelompok kerja yang menggunakan alat bantu dibandingkan dengan kelompok kerja tidak menggunakan alat bantu atau kerja konvensional. Persentase peningkatan volume pekerjaan sebesar $123 \%-127.5 \%$.

\section{KESIMPULAN}

Berdasarkan hasil pelaksanaan kegiatan yang telah dilakukan pada Program Kegiatan Pengabdian bagi Tukang Batu di Kota Kendari ini, dapat disimpulkan beberapa hal sebagai berikut: 
1. Kegiatan yang dilaksanakan mendapat respon positif dari mitra. Hal ini dibuktikan dengan partisipasi dan kerjasama para tukang dan pekerja yang berkenan mencoba, mendengarkan pengarahan hingga menggunakan alat bantu tersebut.

2. Minimnya pelatihan konstruksi gratis, membuat kegiatan ini diapresiasi oleh tukang sehingga berharap kegiatan sejenis dengan cakupan materi lebih luas.

3. Kegiatan yang dilaksanakan sesuai dengan kebutuhan mitra, guna meningkatkan kompetensi tukang bukan hanya sekedar bisa kerja, namun efisien dan efektif kerja.

4. Diperoleh peningkatan volume pekerjaan pasangan dinding batu bata dengan menggunakan alat dibandingkan dengan kerja konvensional sebesar 123\% $127.5 \%$.

5. Kompetensi pekerja konstruksi menjadi syarat mutlak bagi upaya untuk meningkatkan kesejahteraan. Pelatihan yang tepat sasaran akan meningkatkan kompetensi kerja, produktivitas, dispilin, sikap dan etos kerja serta daya saing, sehingga peran dunia akademisi harus bersinergi dengan stakeholder untuk mengadakan pelatihan-pelatihan.

\section{UCAPAN TERIMA KASIH}

Penulis mengucapkan terima kasih kepada Direktur Program Pendidikan Vokasi, Ketua Lembaga Penelitian dan Pengabdian Masyarakat, dan Bapak Rektor Universitas Halu Oleo yang memberi kesempatan dan kemudahan administrasi hingga terselenggaranya kegiatan ini.

\section{DAFTAR PUSTAKA}

Abdul, H. M., \& Vendie, A. (2016). Analisis Produktivitas Tukang Batu Bata pada Pekerjaan Dinding Bata Merah. Jurnal Mahaiswa UII, 469(3), 319323. https://doi.org/10.7868/s0869565216210155

Akmal Abdullah, Mauli Kasmi, Karma, \& Ilyas. (2020). Aplikasi Teknologi Program Pengembangan Produk Unggulan Daerah (PPPUD); Produksi Ikan Hias Karang Lestari di Pulau Barrang Lompo, Makassar, Sulawesi Selatan. Dinamisia : Jurnal Pengabdian Kepada Masyarakat, 4(4), 708714. https://doi.org/10.31849/ dinamisia.v4i4.4122

Dakhli, Z., \& Lafhaj, Z. (2017). Robotic mechanical design for brick-laying automation. Cogent Engineering, 4(1), 1-22. https://doi.org/10.1080/23311916.2017.1361600 
Ekart, H., \& Heinz, U. (2005). Gambar-gambar Infrastruktur Baik \& Buruk. In Bank Dunia, Jakarta. https://doi.org/10.1017/CBO9781107415324.004

Fulford, R., \& Standing, C. (2014). Construction industry productivity and the potential for collaborative practice. International Journal of Project Management, 32(2), 315-326. https://doi.org/10.1016/j.ijproman. 2013.05.007

Hartono, N. et al. (2016). Analisis produktivitas jumlah tenaga kerja pada pekerjaan pasangan bata dengan metode work study. Jurnal Mahasiswa Teknik Sipil, 1(2), 1-6.

Harun, M. (2013). Analisa Produktifitas Tenaga Kerja Pada Pekerjaan Konstruksi Gedung. Jurnal Ilmiah MITSU, 1(2). https://doi.org/10.24929/ft.v1i2.60

Indra, A., Edison, E., Nofrianto, H., \& Kurnia P, S. (2016). The Effect of Pressure in Mold on Physical Properties of Composite Clay/Silica RHA. International Conference on Technology, Innovation, and Society (ICTIS) 2016, 15-21. https://doi.org/10.21063/ictis.2016.1003

Kurniaty, D. R. (2010). Bata Ekspos Sebagai Alternatif Material Dinding Untuk Rancangan Bangunan. Jurnal "Ruang “, 2(2), 45-52.

Ornam, K., Kimsan, M., Ngkoimani, L. O., \& Santi. (2017). Study on Physical and Mechanical Properties with Its Environmental Impact in Konawe Indonesia upon Utilization of Sago Husk as Filler in Modified Structural Fly Ash - Bricks. Procedia Computer Science, 111(2015), 420-426. https://doi.org/10.1016/j.procs.2017.06.043

Prayuda, H., Setyawan, E. A., \& Saleh, F. (2018). Analisis Sifat Fisik dan Mekanik Batu Nata Merah di Yogyakarta (Analysis Physical and mechanical attributes of masonry in Yogyakarta). Jurnal Riset Rekayasa Sipil, 1(2), 94. https://doi.org/10.20961/jrrs.v1i2.20658

Purwanti, H. (2014). Analisis Perbandingan Waktu dan Biaya Dalam Penggunaan Bata Merah dengan M-Panel. Jurnal Teknologi, II. https://doi.org/10.1038/132817a0

Suhendra, \& , Elvira Handayani, M. R. (2015). Karakteristik Fisik Bata Merah dan Kaitannya dengan Analisa Harga Satuan Pekerjaan. Ilmiah, Jurnal Batanghari, Universitas Vol, Jambi, 15(4), 158-163.

Surya Narayana Raju, J. N. S., Srikanth Reddy, S., Raju, P., \& Jagadeep, K. (2019). Red brick dust as a partial substitute to cement in conventional concrete. International Journal of Recent Technology and Engineering, 8(2), 5632-5635. https://doi.org/10.35940/ijrte.B1768.078219

Widiasanti, I., Fridestu, A., Rochyadi, D., \& Anisah. (2018). Faktor Dominan Penghambat Sertifikasi Kompetensi dalam Persepsi Tenaga Terampil di Sektor Konstruksi. Seminar Nasional Teknik Sipil UMJ. Retrieved from https://jurnal.umj.ac.id/index.php/semnastek/article/view/3567/2671

Widjaja Thomas Brunner, I. P. (2012). Pengaruh Penggantian Material Bata Merah Dengan Batako Terhadap Biaya Bangunan. Jurnal Arsitektur Universitas Bandar Lampung, 1(3), 1-6. 